\title{
əon the Internal Variability of Simulated Daily Precipitation*
}

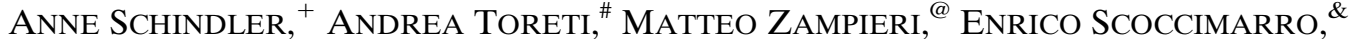 \\ Silvio GuAldi, ${ }^{\&}$ SOPHIE FuKUTOME, ${ }^{* *}$ ElenA XOPLAKI, ${ }^{++}$AND JÜRG LUTERBACHER ${ }^{++}$ \\ ${ }^{+}$Federal Office of Meteorology and Climatology MeteoSwiss, Zurich, Switzerland \\ ${ }^{\#}$ European Commission, Joint Research Centre, Ispra, Italy \\ ${ }^{\circledR}$ Centro Euro-Mediterraneo sui Cambiamenti Climatici, Bologna, Italy \\ ${ }^{\&}$ Istituto Nazionale di Geofisica e Vulcanologia, and Centro Euro-Mediterraneo sui Cambiamenti Climatici, Bologna, Italy \\ ** Federal Office of Meteorology and Climatology MeteoSwiss, Zurich, Switzerland \\ ${ }^{++}$Department of Geography, Climatology, Climate Dynamics and Climate Change, Justus-Liebig University of Giessen, \\ Giessen, Germany
}

(Manuscript received 31 October 2014, in final form 20 January 2015)

\begin{abstract}
Climate model simulations are currently the main tool to provide information about possible future climates. Apart from scenario uncertainties and model error, internal variability is a major source of uncertainty, complicating predictions of future changes. Here, a suite of statistical tests is proposed to determine the shortest time window necessary to capture the internal precipitation variability in a stationary climate. The length of this shortest window thus expresses internal variability in terms of years. The method is applied globally to daily precipitation in a $200-y r$ preindustrial climate simulation with the CMCC-CM coupled general circulation model. The two-sample Cramér-von Mises test is used to assess differences in precipitation distribution, the Walker test accounts for multiple testing at grid cell level, and field significance is determined by calculating the Bejamini-Hochberg false-discovery rate. Results for the investigated simulation show that internal variability of daily precipitation is regionally and seasonally dependent and that regions requiring long time windows do not necessarily coincide with areas with large standard deviation. The estimated time scales are longer over sea than over land, in the tropics than in midlatitudes, and in the transitional seasons than in winter and summer. For many land grid cells, 30 seasons suffice to capture the internal variability of daily precipitation. There exist regions, however, where even 50 years do not suffice to sample the internal variability. The results show that diagnosing daily precipitation change at different times based on fixed global snapshots of one climate simulation might not be a robust detection method.
\end{abstract}

\section{Introduction}

Quantification of internal variability is a prerequisite for the robust detection of climate change (e.g., Knutti and Sedláček 2013; Hegerl and Zwiers 2011). A comparison of a $30-\mathrm{yr}$ period in the present climate with

¿ Denotes Open Access content.

\footnotetext{
* Supplemental information related to this paper is available at the Journals Online website: http://dx.doi.org/10.1175/JCLI-D-1400745.s1.

Corresponding author address: Anne Schindler, Federal Office of Meteorology and Climatology MeteoSwiss, Operation Center 1, CH-8058 Zurich-Airport, Switzerland.

E-mail: anne.schindler@meteoswiss.ch
}

30 years under a future scenario is presented in many studies (e.g., Collins et al. 2013). Important questions arise from these studies: for instance, whether differences between time slices reflect forced changes or whether they are simply induced by internal variability.

Recent works addressing the uncertainty of changes in precipitation include classical signal-to-noise (e.g., Hawkins and Sutton 2011), "time of emergence" (e.g., Maraun 2013), and multimodel or initial conditions (e.g., Rowell 2012; Deser et al. 2012) approaches, all quantifying the role of internal variability. These studies show that internal precipitation variability depends on location and season.

Here, we aim at characterizing internal variability of daily precipitation in the absence of forced changes in climate. We address the following questions: How can internal variability be quantified? How does internal variability of daily precipitation change across space and 
TABLE 1. Model description of the CMCC-CM. For more information we refer the reader to Scoccimarro et al. (2011) and references therein. Expansions of acronyms are available online at http://www.ametsoc.org/PubsAcronymList.

\begin{tabular}{|c|c|c|c|}
\hline Component & References & Resolution & Comments \\
\hline $\begin{array}{l}\text { Ocean: OPA } 8.2 \text { in } \\
\text { OCRA2 global } \\
\text { configuration }\end{array}$ & $\begin{array}{l}\text { Madec et al. (1998), Fichefet } \\
\text { and Morales-Maqueda } \\
\text { (1999), and Roullet and } \\
\text { Madec (2000) }\end{array}$ & $\begin{array}{l}\text { Horizontal resolution of } \\
2^{\circ} \times 2^{\circ} \text { with a meridional } \\
\text { refinement (up to } 0.5^{\circ} \text { ) } \\
\text { toward the equator and } \\
31 \text { vertical levels, } 10 \text { of } \\
\text { which lie within the } \\
\text { upper } 100 \mathrm{~m} \text {. }\end{array}$ & $\begin{array}{l}\text { The model includes a dynamical sea ice } \\
\text { model (Louvain-la-Neuve model), a } \\
\text { free-surface parameterization, and the } \\
\text { Gent and McWilliams (1990) scheme for } \\
\text { isopycnal mixing and a deep ocean. }\end{array}$ \\
\hline $\begin{array}{c}\text { Atmosphere: } \\
\text { ECHAM5 }\end{array}$ & Roeckner et al. (2003) & $\begin{array}{l}\text { Spectral T159 horizontal } \\
\text { resolution, approximately } \\
0.75^{\circ} \times 0.75^{\circ} \text {, and } 31 \\
\text { sigma-pressure levels with } \\
\text { the top level at } 10 \mathrm{hPa} \text {. }\end{array}$ & $\begin{array}{l}\text { The convection parameterization is based } \\
\text { on the mass flux concept by Tiedtke (1989) } \\
\text { and adapted by Nordeng (1994). Moist } \\
\text { processes are treated using a mass } \\
\text { conserving algorithm for the transport (Lin } \\
\text { and Rood 1996) of the different water } \\
\text { species and potential chemical tracers. For } \\
\text { deep convection, an adjustment-type } \\
\text { closure is used with convective activity } \\
\text { expressed in terms of convective available } \\
\text { potential energy. }\end{array}$ \\
\hline $\begin{array}{l}\text { Coupler: } \\
\text { OASIS3 }\end{array}$ & Valcke (2006) & $\begin{array}{l}\text { Coupling frequency of } \\
160 \mathrm{~min} .\end{array}$ & $\begin{array}{l}\text { Heat, mass, and momentum fluxes are } \\
\text { transferred from the atmosphere to the } \\
\text { ocean; SST, sea surface velocities, and ice } \\
\text { cover and thickness are transferred from } \\
\text { the ocean to the atmosphere. No flux } \\
\text { correction is applied to the coupled model. }\end{array}$ \\
\hline
\end{tabular}

seasons? How long do records have to be for a robust description of the underlying climate?

The aforementioned studies quantify the uncertainty of predicting the mean response to forced changes. Therefore, the deviation from the mean behavior is the relevant aspect of internal variability for the question at hand. Here, we argue that variability can be perceived in a more comprehensive manner, that is, as a property of the (entire) distribution, rather than as a deviation from the mean behavior (e.g., Rowell 2012).

We analyze internal variability of daily precipitation in a GCM preindustrial simulation of a stationary climate (section 2a). By studying a stationary climate, in which changes can exclusively be attributed to internal variability, we can identify the shortest time scales necessary to capture it. Thus, we define a minimal record length on different spatial scales and for different regions of the world (section 2b). Seasonal patterns of internal precipitation variability exceeding 30 years, as well as zonal and regional differences in the temporal (interannual to multidecadal) scales, are shown and discussed in section 3. Section 4 concludes the study.

\section{Data and method}

\section{a. Simulated precipitation}

The study is based on 200 years of daily precipitation as simulated by an atmosphere-ocean GCM, CMCC-CM
(Scoccimarro et al. 2011; see Table 1 herein), under preindustrial conditions (CMIP5 experimental setup; Taylor et al. 2012). Throughout the simulation, radiative forcing is the prescribed as prevailing in the 1850s; there are no volcanic eruptions, and land use is constant. A long spinup of 500 years allows the model to reach an equilibrium with the prescribed radiative forcing. Afterward, another 200-yr integration is conducted and the output data corresponding to this stationary preindustrial climate are used for the analysis. We verified that no drift or changepoint exists in the corresponding simulated SST.

The CMCC-CM represents present-day precipitation under observed forcings (no global-scale observations are available for preindustrial times) with equivalent skill to that of other CMIP5 models (e.g., Sillmann et al. 2013; see also Table SM1 in the supplemental material).

\section{b. Minimal record length}

In such stationary setting, distributional differences in precipitation climate, between two different time periods of equal length, can solely arise from internal variability. Any two sufficiently long records should cover the variability range and therefore should not widely differ in terms of distribution. Our purpose is to determine the shortest length of such record, which we call minimal record length (MRL).

We determine the MRL at individual grid cells and for each climatological season separately to avoid the added 

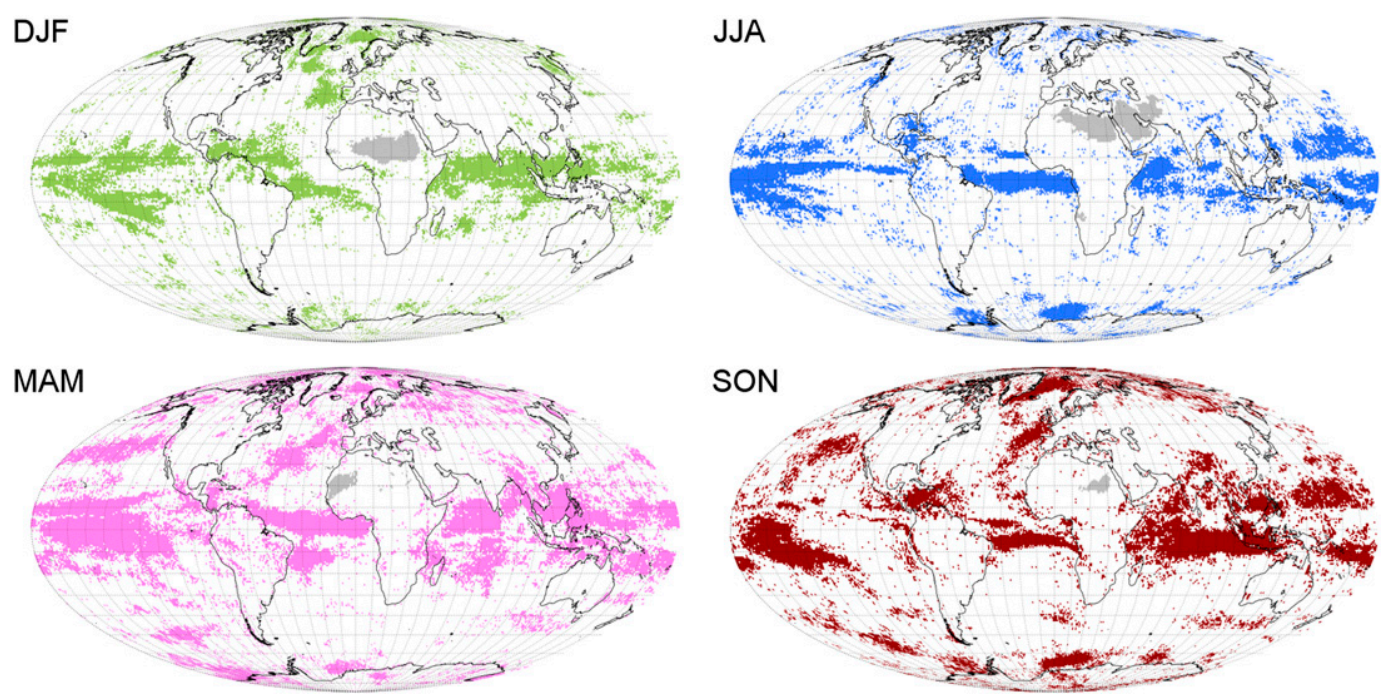

FIG. 1. Seasonal maps of locations at which MRL exceeds 30 years for daily precipitation in (top left) DJF (green), (bottom left) MAM (pink), (top right) JJA (blue), and (bottom right) SON (red). Colored in gray are grid points with too few wet days to perform the analysis.

variability due to the seasonal cycle. For each of the 17 record lengths between 3 and 100 years, a set of 100 records of equal length (extending over $p$ consecutive years) is sampled from the 200-yr simulation by randomly choosing the first year. Within each record, only days with at least $0.01 \mathrm{~mm}$ of precipitation are considered for the analysis.

The daily precipitation distribution within one record is tested against the other 99 records of the same length. The distributional difference between records is assessed with the two-sample Cramér-von Mises test (2sCvM) (Anderson 1962; Csorgo and Faraway 1996). Subsequently, the Walker test (Fisher 1929; Wilks 2006) is performed on the resulting $99 p$ values to account for multiple testing at grid cell level. To determine field significance and to identify the significant grid cells, we apply the BenjaminiHochberg false discovery rate (FDR; Benjamini and Hochberg 1995) at a 5\% rate.

The procedure is iterated from longer to shorter records until we obtain the shortest record length for which records do not differ significantly, the MRL. MRL provides a lower bound below which the full spectrum of internal variability of the stationary climate is not sampled.

We assess the test suite's ability to detect differences between daily precipitation records (see the supplemental material). We examine the ability of detecting differences of various strengths by varying the gamma distributions underlying the simulated samples (the more different, the easier to detect), over short or long records (the longer, the easier to detect), as well as the influence of various rates of temporal (the more periods differ, the easier to detect) or spatial (the more grid cells differ, the easier to detect) mixing (see Figs. SM2 and SM3 in the supplemental material). The behavior of the test is also investigated by using mixtures of gamma distributions to mimic possible mixtures of precipitation-related processes (not shown).

\section{Patterns of internal variability}

\section{a. Internal variability}

As Fig. 1 illustrates, regardless of the season, a period of 30 years - a record length typically used to sample climate-does not suffice to capture the internal variability, for this particular simulation, over large areas of the earth. In particular, this is true all year round for tropical and subtropical ocean grid cells. Conversely, the MRL is shorter than 30 years over much of the midlatitudes.

During boreal winter [December-February (DJF)], North Atlantic grid cells require longer records to characterize the internal variability (Fig. 1), whereas for boreal summer [June to August (JJA)] precipitation, such grid cells are also found in the Caribbean and in the vicinity of the Antarctic (Fig. 1). Both transitional seasons exhibit regions where the MRL exceeds 30 years in the Pacific. Moreover, during boreal spring [March-May (MAM)] and boreal autumn [September-November (SON)] the band of detected internal variability in the subtropics extends farther to the north and south (Fig. 1, bottom). Unlike in winter and summer, internal variability of transitional seasons exceeding a time scale of 30 years can also be detected at land locations, for instance, in northern and southeastern Asia. 


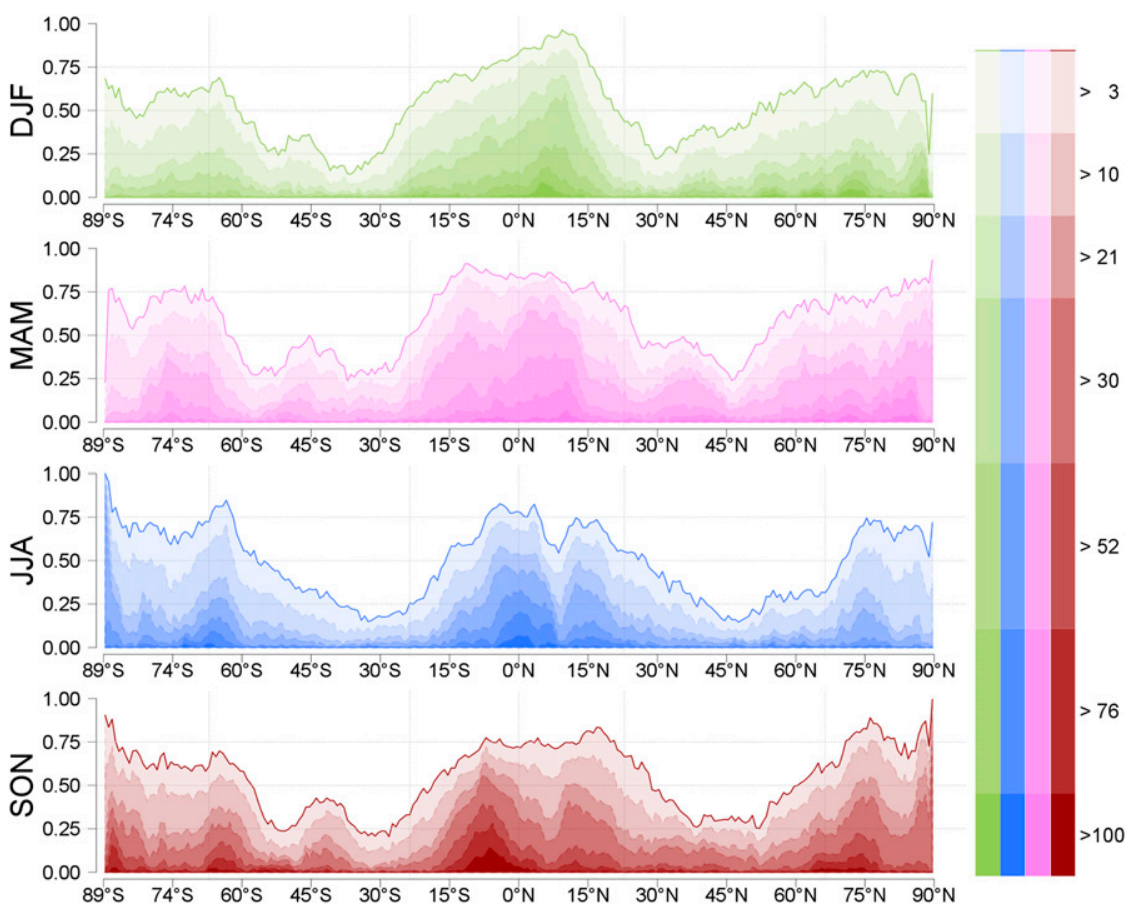

FIG. 2. Zonal plots ( $x$ axis: latitude) of the proportion of grid cells ( $y$ axis) for which MRL is longer than the indicated time scale (yr) for all seasons: (top)-(bottom), DJF (green), MAM (pink), JJA (blue), and SON (red). Time scales of 3, 10, 21, 30, 52, 76, and 100 years are indicated by color shading. For readability, a subset of the analyzed record lengths is only displayed.

Figure 2 shows the meridional distribution of the proportion of grid cells at which the MRL exceeds a specific record length. Focusing on the 30-yr record length, the above mentioned patterns are mirrored in zonal proportions for all four seasons. In general, the tropics and the polar regions stand out as areas with a large proportion of grid cells with detected internal variability (Fig. 2). For all seasons but SON, there is a heavier contribution in the tropics from grid cells in the Northern Hemisphere (NH) than Southern Hemisphere $(\mathrm{SH})$ at all time scales. In SON, however, this is true at time scales up to 21 years, whereas at longer time scales $\mathrm{SH}$ grid cells contribute more strongly to the proportion of grid cells with detected internal variability.

Internal variability can induce distributional changes between records of 100-yr length (Fig. 2). These are located north of Fennoscandia for both DJF and MAM, in the equatorial Atlantic for JJA, MAM, and SON, and during SON in the southern low latitudes (not shown).

Figure 3 shows boxplots summarizing the MRL at land and sea grid cells. Comparing MRL for land and sea grid cells separately underlines the already described longer time scales of internal variability for sea grid cells. While the MRL for the majority of land grid cells is comprised between 3 and 14 years in all seasons, with the highest upper whisker at 52 years (MAM), for sea grid cells the upper quartiles range from 21 (JJA) to 36 years (MAM), with the uppermost whisker reaching 91 years (MAM).

Focusing on land grid cell precipitation variability, Fig. 4 shows summarized MRL results for 26 regions. The abovementioned differences between low, middle, and high latitudes, as well as between main and transitional seasons, thus turn out to be true for most regional results but with notable features (Fig. 4). Regions showing multidecadal internal variability are mainly located in the tropics and subtropics of North America and Asia except for Alaska and northern Asia. These regions show the longest time scales of internal variability in MAM and SON. The Euro-Mediterranean region and western Africa display decadal variability for DJF precipitation and very little for the other seasons. For dry regions, the overall small number of wet days influences the regional results: to apply the test suite for, say, the Sahara, at least 10 years are needed to reach a minimum number of 10 wet days. In keeping with the global patterns, at the regional level, midlatitude precipitation over land varies on shorter time scales than the tropical or high-latitude precipitation (Fig. 4).

\section{b. Discussion}

Our results, based on the analyzed simulation, show that daily precipitation variability over the oceans 

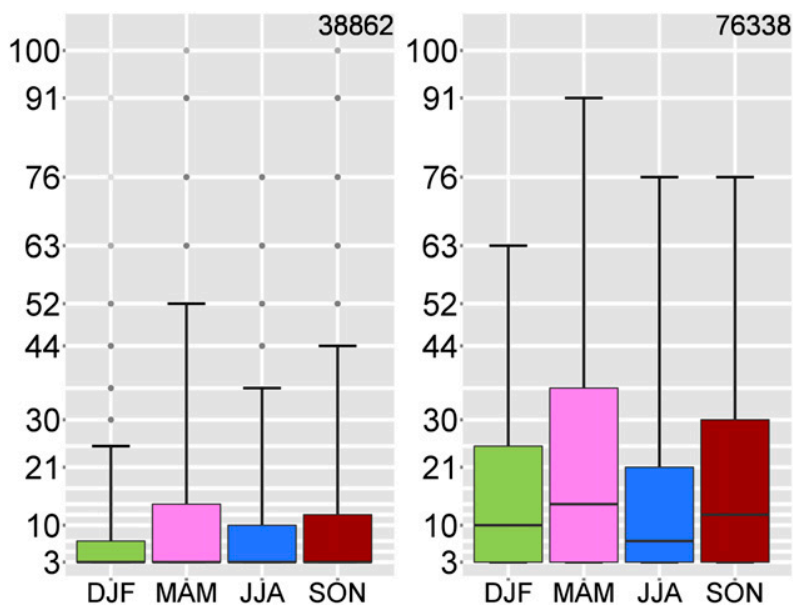

FIG. 3. Seasonal boxplots of MRL values ( $y$ axis) for (left) land and (right) sea grid cells in the four seasons ( $x$ axis): DJF (green), MAM (pink), JJA (blue), and SON (red). For the calculation of the MRL, the field significance is applied to land (sea) grid cells only. Values of 100 years and greater are outside the figure range but were included in the calculation of the boxplots. The counts of land or sea grid cells are given in the upper right corner of each panel. The whiskers of the boxplots are given by the 5th and 95th percentiles. The dots represent outliers shaded according to their number: from few points (light gray) to at least $1 \%$ of all points (black).

exhibits longer time scales than over land. For midlatitude and subtropical oceans this is consistent with Rowell (2012), who identifies internal variability for these areas as the dominant source of uncertainty. For tropical regions, our findings of highest MRL (i.e., detecting variability at long time scales) are neither supported nor contradicted by Rowell's results, which identify modeling uncertainties as dominating the overall uncertainty. The same is true for results by Hawkins and Sutton (2011), according to which the tropics have the smallest signal-to-noise ratio.

In dry regions such as the Sahara, southern Africa, western and central Asia, and northern Australia, the small MRL might be misleading, as the sparse number of wet days coincides with a deficiency of the method to detect small differences in short samples (see the supplemental material). Since the FDR is designed to be conservative, the presence of dependent data could also reduce the detection skill (Ventura et al. 2004). The twosample Kolmogorov-Smirnov test (Smirnov 1939), instead of the $2 \mathrm{sCvM}$, yields less conservative regional MRLs (Fig. SM4 in the supplemental material).

Representing precipitation processes accurately in GCMs is a challenging task (Dai 2006). In particular, different skills in representing large-scale and land surface processes may contribute to the difference between land and ocean precipitation variability. The long (up to
100 years) time scales over the tropics (Fig. 2) might be unreliable, as the GCM's resolution is too coarse for resolving deep convection (Miyamoto et al. 2013).

The climate system displays a wide spectrum of natural modes of oscillation and variability at decadal and multidecadal time scales, especially in the $\mathrm{NH}$ that can affect precipitation: for example, the North Atlantic Oscillation (NAO; Hurrell 1995), the Atlantic multidecadal oscillation (AMO; Kerr 2000), and the Pacific multidecadal oscillation (PDO; Mantua et al. 1997). Therefore, the identified internal variability over the ocean in the NH (Fig. 1; see also Fig. SM1 in the supplemental material) could be related to these phenomena. The regional response to patterns such as NAO or ENSO (Ropelewski and Halpert 1987) or the Indian monsoon can be partially recognized in Fig. 4. Thorough analyses would be required, however, to investigate physical processes responsible for the identified time scales and associated spatial patterns and to evaluate how those processes are reproduced in the climate simulation.

Regions with large MRLs do not correspond to those displaying the highest standard deviation or the highest coefficient of variation (Figs. SM6 and SM7, respectively, in the supplemental material) or vice versa. This is not surprising, as the second moment describes the spread of precipitation for the entire record. While, the MRL by splitting the entire record into smaller time slices is a time measure associated with the sensitivity of the inferred moments to the length of the subrecords.

The discussed aspects of internal variability are relevant for detection and attribution studies. Indeed, this study shows how significant changes at multiple time scales can occur in a stationary climate. Cubasch et al. (2013) define climate change as a persistent change in statistical moments such as mean or variance. In this light, the study of distributional differences-tantamount to changes in all moments at once-for a range of time scales provides information on the persistence of a change: the MRL can be seen as a lower bound for the required duration of this persistent change in order to call a difference a change in climate.

Finally, it we emphasize, once more, that all results are model- and simulation-dependent and cannot be a priori generalized.

\section{Conclusions}

Results clearly show that simulated internal precipitation variability does not act on a single time scale. In the investigated climate simulation, the time scales required to adequately cover the internal variability are longer in the tropics than in the midlatitudes, and they 


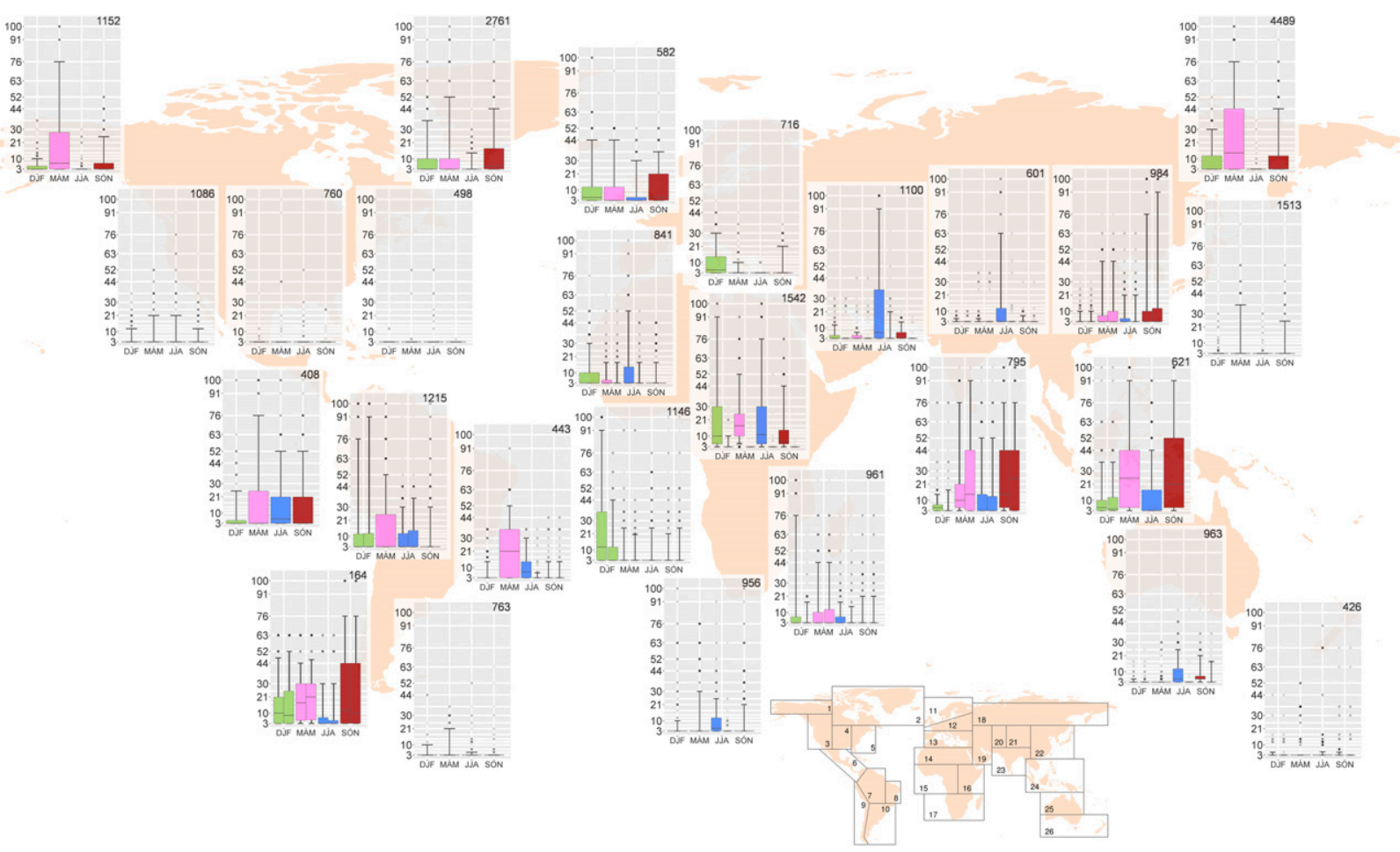

FIG. 4. Seasonal boxplots of MRL at land grid cells of regions as sketched at the bottom right of the figure (Field et al. 2012). See Fig. 3 for color code. For the calculation of the MRL, the field significance is applied only to the region of interest. The counts of land grid cells per region are given in the upper-right corner of each boxplot panel. Two boxplots per season exist where the excessive number of dry days influences the regional results. The additional boxplot on the left-hand side includes the information on the shortest record length with which at least $95 \%$ of the records have at least 10 wet days.

are longer for the transitional seasons than for winter and summer.

The detected variability implies that a characterization of a global, preindustrial precipitation climate with only a 30-yr-long record is not feasible. For many regions, however, especially in the midlatitudes, 30 years seem to suffice for characterizing precipitation in the distributional sense.

The MRL is a conceptually easy way to reveal internal variability; it does not separate dynamically induced variability, periodic behavior, or linear teleconnections, nor does it restrict variability to one time scale. Moreover, the method requires few assumptions and no assumptions regarding the underlying statistical model. The conservative design of the test suite and the general limitations of statistical testing imply, however, that the true time scale of internal variability cannot be fully characterized.

In the context of climate change assessment, we see that internal variability on its own can induce a spurious estimated change in precipitation climate in records as long as 30 years. This demonstrates that diagnosing climate change based on short fixed global snapshots of climate simulations at different times might not be a robust detection method. But our results also imply that any change simulated over a period of the defined MRL or longer could be attributed to a change in forcing and not to internal variability.

It is important to keep in mind, however, that the MRL for daily precipitation depends not only on the season and region, but also on the chosen stationary climate. In fact, the MRL can be expected to differ both from one climate model to another and between equilibria of the climate system. A specifically designed long-run multimodel experiment would be necessary to better understand and characterize internal variability. Thus, comparing MRL patterns of an ensemble of GCM simulated daily precipitation in stationary control runs might initiate and stimulate further discussions on uncertainty of climate projections and climate change.

Acknowledgments. We acknowledge the WCRP's WGCM (responsible for CMIP), the project "Climate Change and Extreme Weather in Hesse" funded by the Hessian Centre on Climate Change, and M.Z., E.S, and S.G. acknowledge funding from the Italian Ministry of 
Education, University and Research, and the Italian Ministry of Environment, Land and Sea under the GEMINA project.

\section{REFERENCES}

Anderson, T. W., 1962: On the distribution of the two-sample Cramér-von Mises criterion. Ann. Math. Stat., 33, 1148-1159, doi:10.1214/aoms/1177704477.

Benjamini, Y., and Y. Hochberg, 1995: Controlling the false discovery rate: A practical and powerful approach to multiple testing. J. Roy. Stat. Soc., 57B, 289-300.

Collins, M., and Coauthors, 2013: Long-term climate change: Projections, commitments and irreversibility. Climate Change 2013: The Physical Science Basis, T. Stocker et al., Eds., Cambridge University Press, 1029-1136.

Csorgo, S., and J. J. Faraway, 1996: The exact and asymptotic distributions of Cramér-von Mises statistics. J. Roy. Stat. Soc., 58B, 221-234.

Cubasch, U., D. Wuebbles, D. Chen, M. Facchini, D. Frame, N. Mahowald, and J.-G. Winther, 2013: Introduction. Climate Change 2013: The Physical Science Basis, T. Stocker et al., Eds., Cambridge University Press, 119-158.

Dai, A., 2006: Precipitation characteristics in eighteen coupled climate models. J. Climate, 19, 4605-4630, doi:10.1175/ JCLI3884.1.

Deser, C., A. Phillips, V. Bourdette, and H. Teng, 2012: Uncertainty in climate change projections: The role of internal variability. Climate Dyn., 38, 527-546, doi:10.1007/ s00382-010-0977-x.

Fichefet, T., and M. A. Morales Maqueda, 1999: Modeling the influence of snow accumulation and snow-ice formation on the seasonal cycle of the Antarctic sea-ice cover. Climate Dyn., 15, 251-268, doi:10.1007/s003820050280.

Field, C. B., and Coauthors, 2012: Managing the Risks of Extreme Events and Disasters to Advance Climate Change Adaptation. Cambridge University Press, 582 pp.

Fisher, R. A., 1929: Tests of significance in harmonic analysis. Proc. Roy. Soc. London, 125A, 54-59, doi:10.1098/rspa.1929.0151.

Gent, P. R., and J. C. McWilliams, 1990: Isopycnal mixing in ocean circulation models. J. Phys. Oceanogr., 20, 150-155, doi:10.1175/1520-0485(1990)020<0150:IMIOCM > 2.0.CO;2.

Hawkins, E., and R. Sutton, 2011: The potential to narrow uncertainty in projections of regional precipitation change. Climate Dyn., 37, 407-418, doi:10.1007/s00382-010-0810-6.

Hegerl, G., and F. Zwiers, 2011: Use of models in detection and attribution of climate change. Wiley Interdiscip. Rev.: Climate Change, 2, 570-591, doi:10.1002/wcc.121.

Hurrell, J., 1995: Decadal trends in the North Atlantic Oscillation: Regional temperatures and precipitation. Science, 269, 676679, doi:10.1126/science.269.5224.676.

Kerr, R. A., 2000: A North Atlantic climate pacemaker for the centuries. Science, 288, 1984-1985, doi:10.1126/science.288.5473.1984.

Knutti, R., and J. Sedláček, 2013: Robustness and uncertainties in the new CMIP5 climate model projections. Nat. Climate Change, 3, 369-373, doi:10.1038/nclimate1716.

Lin, S. J., and R. B. Rood, 1996: Multidimensional flux-form semiLagrangian transportation schemes. Mon. Wea. Rev., 124, 20462068, doi:10.1175/1520-0493(1996)124<2046:MFFSLT>2.0.CO;2.
Madec, G., P. Delecluse, M. Imbard, and C. Lévy, 1998: OPA 8.1 Ocean General Circulation Model reference manual. Note du Pôle de Modélisation 11, Institut Pierre-Simon Laplace, 91 pp.

Mantua, N. J., S. R. Hare, Y. Zhang, J. M. Wallace, and R. C. Francis, 1997: A Pacific interdecadal climate oscillation with impacts on salmon production. Bull. Amer. Meteor. Soc., 78, 1069-1079, doi:10.1175/1520-0477(1997)078<1069: APICOW $>2.0 . \mathrm{CO} ; 2$.

Maraun, D., 2013: When will trends in European mean and heavy daily precipitation emerge? Environ. Res. Lett., 8, 014004 , doi:10.1088/1748-9326/8/1/014004.

Miyamoto, Y., Y. Kajikawa, R. Yoshida, T. Yamaura, H. Yashiro, and H. Tomita, 2013: Deep moist atmospheric convection in a subkilometer global simulation. Geophys. Res. Lett., 40, 4922-4926, doi:10.1002/grl.50944.

Nordeng, T. E., 1994: Extended versions of the convective parametrization scheme at ECMWF and their impact on the mean and transient activity of the model in the tropics. ECMWF Research Department Tech. Memo. 206, 41 pp.

Roeckner, E., and Coauthors, 2003: The atmospheric general circulation model ECHAM5. Part I: Model description. MPI Rep. 349, 127 pp.

Ropelewski, C. F., and M. S. Halpert, 1987: Global and regional scale precipitation patterns associated with the El Niño/Southern Oscillation. Mon. Wea. Rev., 115, 1606-1626, doi:10.1175/ 1520-0493(1987)115<1606:GARSPP > 2.0.CO;2.

Roullet, G., and G. Madec, 2000: Salt conservation, free surface, and varying levels: A new formulation for ocean general circulation models. J. Geophys. Res., 105, $23927-23942$, doi:10.1029/2000JC900089.

Rowell, D. P., 2012: Sources of uncertainty in future changes in local precipitation. Climate Dyn., 39, 1929-1950, doi:10.1007/ s00382-011-1210-2.

Scoccimarro, E., and Coauthors, 2011: Effects of tropical cyclones on ocean heat transport in a high-resolution coupled general circulation model. J. Climate, 24, 4368-4384, doi:10.1175/ 2011JCLI4104.1.

Sillmann, J., V. V. Kharin, X. Zhang, F. W. Zwiers, and D. Bronaugh, 2013: Climate extremes indices in the CMIP5 multimodel ensemble: Part 1. Model evaluation in the present climate. J. Geophys. Res. Atmos., 118, 1716-1733, doi:10.1002/ jgrd.50203.

Smirnov, N. V., 1939: On the estimation of the discrepancy between empirical curves of distribution for two independent samples. Bull. Math. Univ. Moscow, 2, 2.

Taylor, K. E., R. J. Stouffer, and G. A. Meehl, 2012: An overview of CMIP5 and the experiment design. Bull. Amer. Meteor. Soc., 93, 485-498, doi:10.1175/BAMS-D-11-00094.1.

Tiedtke, M., 1989: A comprehensive mass flux scheme for cumulus parametrization in large-scale models. Mon. Wea. Rev., 117, 17791800, doi:10.1175/1520-0493(1989)117<1779:ACMFSF>2.0.CO;2.

Valcke, S., 2006: OASIS3 user guide (PRISM 2-5). PRISM Support Initiative 3, Tech. Rep. CMGC/06/73, CERFACS, 64 pp.

Ventura, V., C. J. Paciorek, and J. S. Risbey, 2004: Controlling the proportion of falsely rejected hypotheses when conducting multiple tests with climatological data. J. Climate, 17, 43434356, doi:10.1175/3199.1.

Wilks, D., 2006: On "field significance" and the false discovery rate. J. Appl. Meteor. Climatol., 45, 1181-1189, doi:10.1175/ JAM2404.1. 